\title{
Epistemological and Ontological Challenges of Transnational Foundation Year Medical Students
}

\author{
C. Holden (Corresponding author) \\ Royal College of Surgeons in Ireland, Bahrain \\ E-mail: cholden@rcsi-mub.com \\ E. Anand, W. Maddison, E. Tawash \& J. Hughes \\ Royal College of Surgeons in Ireland, Bahrain
}

Received: September 17, 2017 Accepted: October 15, 2017 Published: November 20, 2017

doi:10.5296/ijld.v7i4.11863

URL: https://doi.org/10.5296/ijld.v7i4.11863

\begin{abstract}
This paper investigates the journey embarked upon by foundation year medical students in order to adapt to new ways of learning, knowing and realizing self-determination as they navigate the new situated spaces of a transnational medical university in the Middle East. Drawing on a body of research carried out in this university, and with reference to wider literature on transnational education, this paper develops insights and makes recommendations on how to support local Arab students from Arabic secondary schools who enter transnational medical education 'at home'. The discussion considers an important component of this as being the shift in this context from previous learning through the medium of Arabic to tertiary level learning in English. It is argued that the transition of transnational students can be mapped through ontological and epistemological lenses through a journey from 'known space' to 'new place'. A tri-support model which demonstrates this transition is presented which can be usefully applied to other transnational educational contexts.
\end{abstract}

Keywords: transnational, medical, transition, known space, new place, tri-support model 


\section{Introduction}

Starting medical school is challenging enough for a student in his/her own cultural context (Dutton et al., 2010), so it can be an extremely daunting experience for a student entering a learning space grounded in a very different culture and language (Holden, 2015) from that of 'home'. These students are required to develop a toolkit of new cultural competencies and coping strategies in order to successfully navigate within and through the new and unknown space of transnational education. In this specific context, such competencies and strategies are focused on the linguistic shift from students' native Arabic language towards the lingua franca of medicine, which is English (Kane, 2014).

The discussion in this paper is contextually situated in an Irish medical school geographically located in the Middle East, conceptualising the concept of the 'new space' of transnational education referred to in this paper. We introduce the development of a tri-support model of the transitional, transnational student journey in this context, which traces the ontological and epistemological shift experienced by local foundation year medical students. 'Local' in this context refers to the countries in the Arabian Gulf forming the Gulf Cooperation Council.

Transposing education which is developed, informed and constructed on the values of one cultural context and delivered in another is not without its problems; in particular the challenges this poses for students, and raises the following questions to be addressed:

1) What are the epistemological and ontological challenges that local foundation year medical students have to navigate on entering an Irish transnational medical university located in the Middle East?

2) What is a suitable model that supports this transnational, transitional journey?

An emerging body of research from this Irish medical university located in Bahrain focuses on the first-year student experience in transnational education (Holden-Rachiotis \& Otoom, 2015; Maddison, 2015; Maddison, 2016; Holden, 2015, Hayes et al., 2011; Hayes et al., 2013; Leksandar-Hayes, 2013) and provided the starting point for the investigation of these questions.

This research identified that there were specific gaps to be bridged by new students, and points to marked epistemological and ontological shifts occurring when local students first enter transnational education. Findings indicated that the first-year of medical school, in particular the first six months, is the most challenging time for local students in transnational medical education, and reflect international literature on the transition to higher learning (Kruzicevic at al., 2012; Arulampulam et al., 2004a). However, in this specific context in the Middle East, the first-year transitional experience is framed by the complexities of differences involved when local students move from an Arabic, gender segregated government school learning environment, to a very different English language, western learning environment (Lindley at al., 2013). This process involves the negotiation of significant social, academic and personal challenges or gaps which must be overcome early in a student's academic career (Trotter \& Roberts, 2006). 


\section{Macrothink}

This discussion focuses on the language gap encountered by Arabic speaking foundation year medical students learning in English, and proposes that the transition from the students' native Arabic language, to learning medicine through English, is not simply a matter of language adjustment, but comprises adapting to new ways of learning, knowing and being; redefining academic and social relationships; and moving into new spaces. These aspects create notable ontological and epistemological challenges which frame the move from 'known space' to 'new place'.

\section{Methodology}

A social constructivist epistemology informs the approach to this research, rooted in the ontological position of the individual creating, understanding and positioning of self in their world, and the epistemological position of knowledge being personal, subjective and unique, which is made sense of through continuous shifting and sifting of interactions with and interpretations of their world. This project follows Guba \& Lincoln (1998) in that this research is relativist, transactional and subjectivist. Literature emerging from the Middle Eastern transnational educational context was analysed using thematic analysis (Braun \& Clarke, 2006). Themes identified were collated through semantic content and interpreted by theorizing patterns and implications (Patton, 1990). Through the process of theorizing, the following themes were identified: English language; adaptation to new ways of learning and knowing; redefining relationships; moving into new spaces; teaching and learning support; peer support, and student development and wellbeing. These themes are presented below.

\section{Findings}

Transition when commencing university in one's home country includes the academic transition occurring from secondary level learning to tertiary level, as well as social transition from a known environment into the unfamiliar as new relationships need to be constructed (Tinto, 1993). However, transition in a transnational location also comprises the complexities of working in a different language; dealing with the shock of understanding a new cultural framework, and developing self-determination, self-efficacy, reflexivity and personal agency in order to succeed in this new world (Holden, 2015; Maddison, 2016). Gaps of difference confronted during this transition can be summarized in a synchronous two-step bridging process, set out in the table below and which comprises both the academic and cultural components of transition. Transition is defined here as the experience of moving from an Arabic secondary school education to a European medical university model, where learning is delivered in English. 
Table 1. Academic and cultural gaps bridged by transnational Middle Eastern first-year medical students during the transition period (Maddison, 2016)

\begin{tabular}{ll}
\hline Academic Bridging & Cultural Bridging \\
\hline Overcoming English language challenges & Overcoming culture shock \\
Adapting to new ways of learning and knowing & Adapting to new ways of being \\
Developing self-determination and & Developing skills of reflexivity and personal agency \\
self-efficacy as a learner & \\
Redefining relationships in the classroom: & Redefining social relationships: \\
-Faculty members as role models & -Reconciling Arab Islamic values \\
-Classmates as peers and colleagues & -Reshaping gendered boundaries \\
Moving in new spaces: & Moving in new places: \\
-Campus as a transnational habitus & -Cognitive and conceptual stretching \\
\hline
\end{tabular}

The transitional experience expressed in Table 1 raises not only epistemological issues of how students construct new knowledge in a new space, but also ontological issues of how their educational experiences impact their sense of being in the world. In the following discussion, we consider the impact of English language; adaptation to new ways of learning, knowing and being; redefining academic and social relationships; and moving into new spaces.

\subsection{English Language}

It is commonly assumed that a student will be seamlessly culturally assimilated into the transnational institution, with the institution construing 'the home identities and languages as problems that have to be fixed' (Badenhorst \& Kapp, 2013:466). What is not considered in this approach is that the dominant discourse of the transnational institution is vastly different in terms of values, attitudes and beliefs, resulting in students confronting questions around their own sense of identity. To better understand the knowledge construction of local foundation year medical students, we need to understand the investment students make in their learning in order to 'fit'. The degree of fit between the pedagogical-didactical approach followed in secondary schools, and that used in undergraduate programmes, influences first-year achievement (Torenbeek et al., 2011). Fit and its effect on integration and performance is a highly relevant issue to this transnational medical school, where a high number of students enter from a rote learning, local Arabic secondary school background. Research by Leksandar-Hayes (2013) considers the scientific knowledge fit between Arabic secondary schools in Bahrain and this medical school to be appropriate in terms of content and standard. However, language transition, managing the breadth and depth of the curriculum, understanding delivery and assessment methods, and adapting learning styles remains problematic for foundation year students in this context. Local Arabic speaking students are required to undergo an epistemological U-turn from the rote learning transmission of knowledge experienced at Arabic Secondary Schools to becoming reflective, active learners in a transnational western medical school. Understanding, learning and communicating through English language is a major transitional step to be taken by these students. This transition period can be as short as a number of days or extending to many months (Holden, 2015). 


\section{Macrothink Institute ${ }^{\text {TM }}$}

Adjustment from learning in a native language and then having to use a second language is not an inconsequential event. Foundation year medical students at this university frequently utilize a mechanism of translation to aid their move from learning through their first language towards learning in a second language (Holden, 2015). Lindley et al., (2013) also describe medical students applying methods of intensive translation from their mother tongue into English during their first-year experience. Translation is a strategy which is employed by many students in the initial weeks of their educational journey, even by those who have a good level of English. Students in this university cited the pace of delivery and accent of lecturers, use of colloquialisms and engaging with professional medical language as being major challenges in their linguistic journey. Existing research confirms that language challenges affect the transition of non-native speakers of English into higher education (Biggs 1998; Wu \& Hammond, 2011), so students who have to understand new and often complex medical terminology in English face an added burden.

It is also clear that the a student's level of English on entry to medical school, as measured by the International English Language Testing System (IELTS) examination, impacts the level of academic success achieved. Hayes \& Farnill (1993) demonstrated that English language ability is a strong predictor of success and this is supported through our own research into Foundation Year performance.

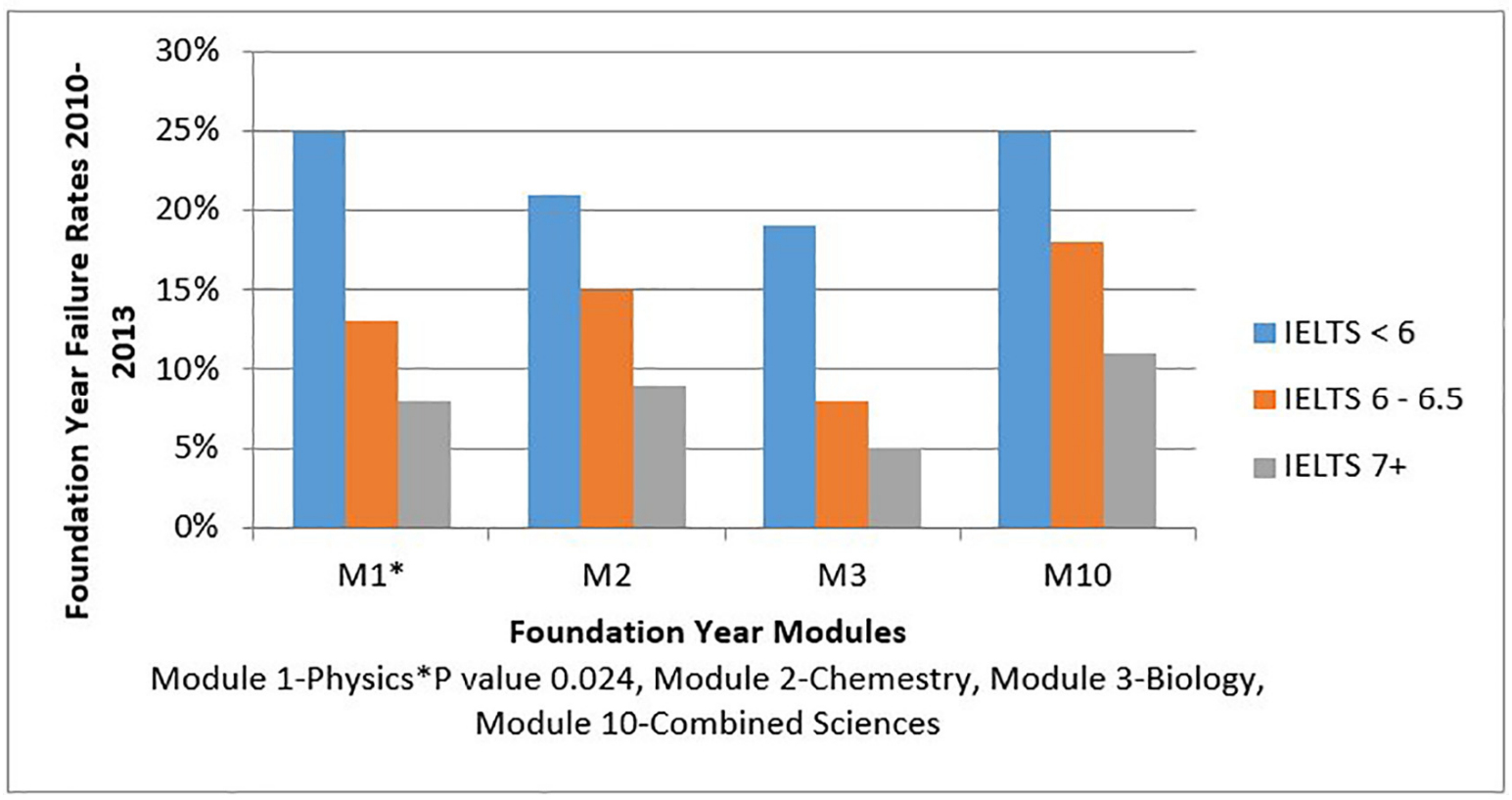

Figure 1. The impact of English language measured by IELTS on Foundation Year failure rates 2010-2013 (Holden, 2015)

Figure 1 illustrates the link between the English language level of students and their academic performance in the Foundation Year core modules of Physics (M1), Chemistry (M2), Biology 
(M3) and Integrated Sciences (M10). The data shows that the higher the students' English language levels, the better the performance in these modules. The Physics module in Foundation Year (M1) is shown to have a P value statistical significance of 0.024; the other modules, although not displaying statistical significance, do show a significant trend. This finding is of importance as it shows that the move towards learning science through English as a second language is not inconsequential and can impact pass and failure rates, with higher English language proficiency being associated with higher pass rates.

\subsection{Adaptation to New Ways of Learning and Knowing}

Local students in this Middle Eastern context are confronted with both academic and cultural bridges to be crossed upon entering a transnational learning environment. At an early stage in the transition period students begin to develop awareness of their own changing subjectivity and start to re-contextualize their previous assumptions (Haw, 2011; Marginson, 2014) in their new environment. During the first semester in particular, students require tools and mechanisms within this specific cultural and gendered learning environment to develop aspects of self-determination and resilience which will lead to an empowering and successful transformative learning experience (Maddison, 2015).

Research into the first-year learning experience indicates that self-determination is an important factor in outcomes of student success (Beachboard et al., 2011; Ryan \& Deci, 2000; Tinto, 1994; Wenger, 1998). Self-determination as a theory of motivation posits that in order for students to succeed, certain needs have to be met. These are autonomy, competence and relatedness (Deci \& Ryan, 2002; Milyavskaya \& Koestner, 2011). Findings from a focus group study (Maddison, 2015) indicate that this transnational medical school provides an appropriate environment, or habitus (Bourdieu, 1991), which meets local students' needs for the fostering of self-determination, and which promotes independence, personal and professional development, and belongingness. Further development of students' skills such as critical reflection and self-awareness (Hanson et al., 2011) also leads to a deeper understanding of motivations, power relationships, and ethical issues (Baxter-Magolda, 1992) and impacts in a local context that supports students' personal and academic achievements, and ultimately dovetails into their professional practice. To successfully navigate the path to new ways of learning, knowing and construction of self-determination, timely and suitable support is required, combined with educational sessions which develop skills such as critical reflection and self-awareness - skill sets which have not been previously addressed in the students' Arabic secondary school experience. The table below highlights the differences between students' Arabic government secondary school experience and their western medical university experience. 
Table 2. Summary of comparison in learning environments of an Arabic government school and a western medical university as experienced by students (Maddison, 2015)

\begin{tabular}{|c|c|}
\hline Arabic Government High School & Western Medical University \\
\hline Didactic, structured learning & Reflective, active learning \\
\hline Individual effort, segregated schooling & Teamwork, mixed gender groups \\
\hline Learning in Arabic & Learning in English \\
\hline Rote learning, dependent on teachers & Critical thinking, independent learning \\
\hline Limited intercultural exposure & Wide intercultural exposure \\
\hline $\begin{array}{l}\text { Externally regulated and motivated (through families, } \\
\text { teachers, religious leaders, authority figures such as } \\
\text { fathers) }\end{array}$ & $\begin{array}{l}\text { Internally regulated and motivated (through } \\
\text { self-efficacy, self-determination and personal agency) }\end{array}$ \\
\hline Fixed mindset - in the moment & Growth mindset - forward thinking \\
\hline Strong family influence/collectivistic focus & Looser family influence/individualistic focus \\
\hline $\begin{array}{l}\text { Arab Islamic values and norms inform, drive and } \\
\text { maintain embedded traditional beliefs and behaviors; } \\
\text { cultural and religious conformity }\end{array}$ & $\begin{array}{l}\text { Western culture pervades; encouragement of personal } \\
\text { development and change; cultural and religious } \\
\text { diversity }\end{array}$ \\
\hline
\end{tabular}

It is important for educators in the transnational education field to acknowledge that letting go of previous mindsets and taken-for-granted assumptions can be uncomfortable for students, but tapping into their previous educational experience and supporting their situated knowledge through the creation of a robust and culturally appropriate framework can enhance their learning (Gay, 2010) and sustain a transformative educational encounter (King, 2004). This points to the importance of facilitating students' skills in critical reflection (Hanson at al., 2011; Marlowe et al., 2014; Stutz et al., 2015) during the transition, so that they gain a deeper insight and understanding of their transformative learning experiences as key stakeholders in the transnational education process (Patel \& Lynch, 2013).

\subsection{Redefining Relationships}

The move into a transnational medical university strikes at the very heart of the students' Arab culture. This heart is the family, which not only has great influence over an individual in the Middle East context (Holden, 2015), but also frames their sense of being. During the transition period from secondary school to tertiary education, students reassess and redefine two groups of relationships in particular; that of family and faculty (Maddison, 2015). This process is not without its challenges. Students often report guilt issues when they have to distance themselves from their families, and they find themselves drawn towards others outside their established family and social network who share similar experiences. Medical school ethnographies highlight that students may become withdrawn from their family environment and other friends 'on the outside' due to the deep acculturation process that is experienced (Sinclair, 2007), and this is indeed the case in this Middle Eastern transnational context. This is supported by Kane (2014:104) who discusses estrangement between a Qatari medical student and her parents as being 'indicative of the intense acculturation process' and makes reference to the 'insiders' (medical students) and 'outsiders' (family members). Such perspectives 
indicate a shift in an ontological perspective. As students progress academically in their new transnational learning environment, this positioning can cause internal conflict as individuals have to wrench themselves away from cultural expectations and known spaces, and embrace a new sense of self as a medical student.

However, such ambiguities open up new hybrid possibilities of being, comprising aspects of both continuity and change (Enns, 2010), as students come to understand their changed sense of self. Within this process both Arab and western faculty are reported to be important role models in students' educational experience (Dornan et al., 2015; Maddison, 2015; Sohail \& Shaikh, 2004). They are the depiction of what the new space holds, a space of extensive knowledge and professional persona. En route to this new space, foundation year medical students 'experiment with their medical personas and internalize professional values through the mimicry of habitual behaviours, attitudes and actions as exhibited by their mentors as they work alongside them' (Kane, 2014:107). This experimentation creates the mold that forms the reality of the move to a 'medical habitus' (Kane, 2014:108).

As the transnational transition nudges a student away from the known and towards the new, he/she is not alone. Alongside is a group of peers who are experiencing the same ontological and epistemological challenges. A necessary 'network of peers' (Tinto et al., 1993:18) is established in this transnational space, which propels students forward and provides them with opportunities for the development of self-determination (Brooks \& Young, 2011; Houser \& Frymier, 2009; Wigfield \& Eccles, 2002). It is this group of students who share the same background that creates the 'us' described by Kane (2014:104). It is this 'us' which is the fundamental part of the new space, leaving the 'them' (ibid) behind. The shared language of the new space for these medical students is not only English but 'Doctorese' (ibid), a specific linguistic illustration that demarcates a transnational medical student from their previous conceptual space.

\subsection{Moving into New Spaces}

The model which emerges from the analysis of the literature and the discussion within this paper demonstrates the move experienced by students from a known space into a new space (Figure 2). Transnational space can be defined as a theoretical construct which encapsulates elements of this transition. The known space of secondary school is defined by Arabic language and traditions, dependent learning models, family influence, and external regulation, and the new space involves an adaptation to independent learning through English, personal development, and cultural and religious diversity.

This transitional, transnational journey is supported by student experience of their academic programme and their engagement with developmental and support programmes provided at the university. Educators involved in transnational educational practice have to develop a culturally appropriate, responsive and transformational pedagogy (Kim \& Slapac, 2015), with epistemological and ontological gaps and challenges identified in context, so that students can be guided into their new transnational place. Interventions need to be purposefully 'frontloaded' in the first semester to bolster the student transitional journey through their first academic year. Three critical areas of support we have identified are: teaching and learning; 


\section{Macrothink}

International Journal of Learning and Development

ISSN 2164-4063 2017, Vol. 7, No. 4

peer support; and student development and wellbeing. These support areas are illustrated below as the supporting foundations on which to scaffold epistemological and ontological changes.
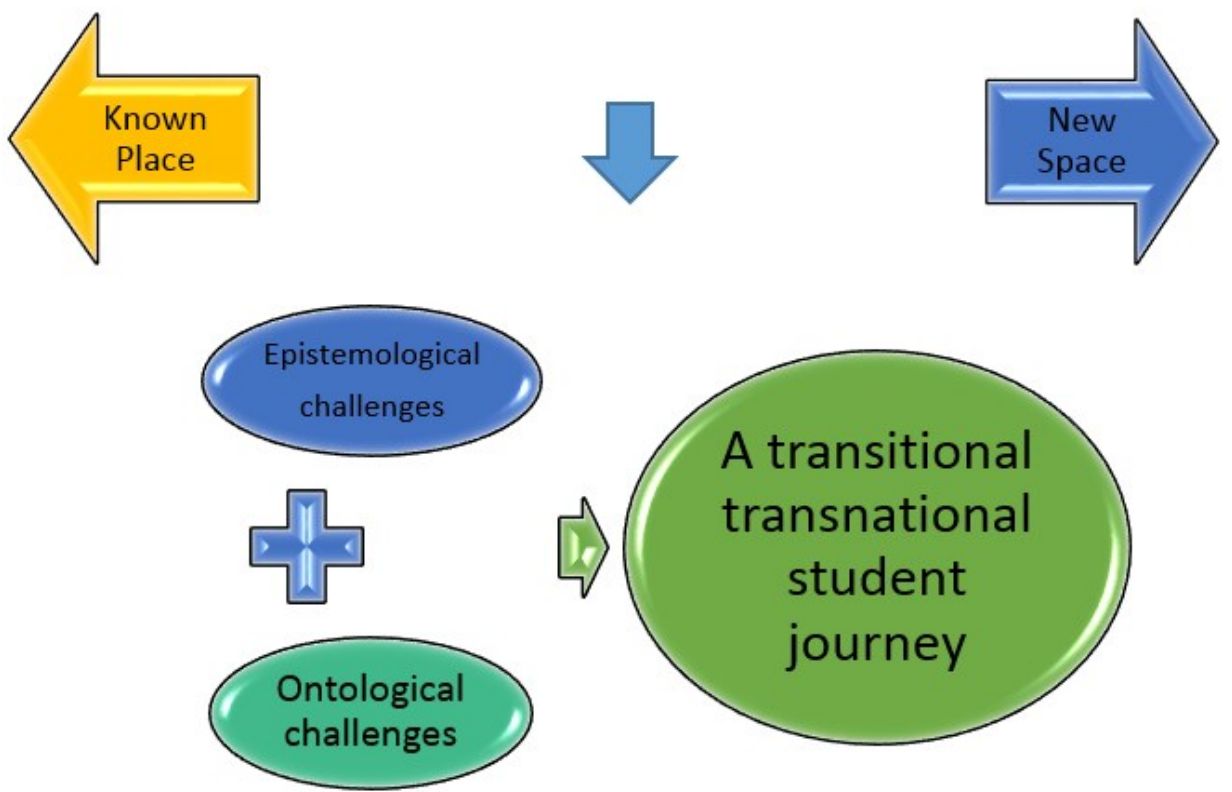

Teaching \& Learning Support

Faculty - Personal Tutors - Learning Tutors

Peer Support

Buddy Programme - Peer Assisted learning - Student Council Clubs \& Societies - Peer Led Sessions

Student Development \& Wellbeing Support

Personal Development Workshops -Engagement \& integration activities -Counselling Cultural Diversity awareness

Figure 2. Tri-Support Model of Known Space to New Place.

This tri-support model supports students through the epistemological and ontological challenges encountered in their transitional move from known space to new place. Studies of first-year learning show that the initial experiences of a student are critical as they ultimately impact student satisfaction and persistence (Pitkethly \& Prosser, 2001). Capturing engagement and early investment of the student into his/her learning can impact positively on the student journey. Yorke \& Longden (2007) found that initial misconceptions about their chosen course of study by first-year students led to a lack of preparedness. Although little literature exists in the international context, findings indicate that social networks are an important component of a classroom environment. Factors such as sharing a nationality and culture, as well as sharing a 
language, seem to impact in the building of student networks, as does the commonality of following the same programme. Networks have been described as 'forming and dissolving throughout the semester based on multiple factors, rather than evolving towards one coherent network' (Taha \& Cox, 2016:191). Time is also an affective factor in helping to develop these connections. Within the teaching environment, mixing students through group work and by engaging them in complex group tasks such as video making, can strengthen these ties. We now consider each critical area of support in the tri-support model, namely teaching and learning; peer support; and student development and wellbeing.

\subsection{Teaching and Learning Support}

Early exposure to student activities and access to key academic staff can set the scene for positive student interactions. Interaction with first-year teaching staff can take place before the start of the academic year, through on-line resources and dedicated links in social media. The months prior to the start of the academic year can mark a period of great student excitement and also an opportunity to capture this positive energy. Establishing academic/student contact during this time and maintaining it throughout the first-year experience can provide not only increased communication avenues but a deepening understanding of learning expectations, both academic and social, rather than just focusing on an entirely cognitive process (Taha \& Cox, 2016).

Attentiveness of academic staff is required - academics could be defined as 'specialists' in first-year learning. Such specialists require dedicated contracted time for activities which focus on creating collaborative and inclusive spaces in which students are required to share their beliefs, knowledge and experience (Gale \& Parker, 2014). The foundation year medical programme at this university is designed to provide students with the opportunity to make the necessary transitions to studying year one medicine. Two main themes within the foundation year curriculum are professionalism, which includes English language, and Biomedical Sciences. The professionalism theme allows students to develop their communication, collaboration and critical thinking skills whilst developing greater awareness in the areas of medical ethics, communication and cultural diversity. The basic sciences of physics, chemistry and biology are delivered within a medical context and often in an integrated format, thus allowing students to adjust to the multi-subject format of the following academic year. Learning events are comprised of didactic lectures, student-centred tutorials, laboratory practicals, online discussions, quizzes, assignments, group projects and presentations. As a component of the student centred tutorials, a guided inquiry approach to learning - POGIL (Process orientated guided inquiry learning) is employed in certain sections of the curriculum.

Local foundation year students at this university generally experience a level of independent learning they have not encountered to date in their academic development, delivered within a safe, supported context. Each academic team member operates an open door policy as opposed to formal office hours which are more commonly implemented in other universities. This provides students who require assistance or guidance with a high level of support on a one to one basis. Academic support for all students is provided through formal feedback and feedforward sessions on interim and summative assessments. 


\section{Macrothink}

International Journal of Learning and Development

ISSN 2164-4063

2017, Vol. 7, No. 4

The Library and Learning Resource Center (LLRC) of this university offers user education and information literacy support to students through the entirety of their academic career. Students must assimilate understanding and develop skills in knowledge bases, understand their purpose and learn to use search tools to retrieve just-in-time information. There are two main drivers to promote information literacy: the emergence of evidence based practice in the health sciences arena; and the skills needed to succeed in a knowledge based society. The Information Services Department in the Library provides highly supportive curriculum integrated information literacy sessions for students.

\subsection{Peer Support}

Apart from an active student council which operates a range of clubs and societies for student social engagement and provides opportunities for network building and peer support, this university offers two student led programmes which provide valuable peer support.

The Peer Assisted Learning (PAL) programme is a student-to-student support scheme that underpins both academic as well as personal and professional development. Volunteer students are trained as PAL tutors to facilitate the learning of other students. PAL sessions are run on campus for foundation year students by their peers, selected as tutors on the basis of their academic grades. The character of PAL sessions for foundation year students is one of comfortable, cooperative and collaborative academic learning. The voluntary sessions are timetabled, announced to all students concerned and focused around discussion, demonstration and interaction, all of which enhance existing student knowledge. Individual students benefit through the enhancement of their knowledge and skills, as well as building confidence and self-esteem and cross-cultural awareness though interaction with peers and being able to discuss topics and ask questions within a safe and friendly learning environment. This develops the ability to master course concepts, study and cognitive skills in an environment different from the formal lecture hall. PAL Tutors benefit by sharing knowledge and thus reinforcing their own prior learning, and have the opportunity to develop personal and professional skills such as leadership, planning, organization and communication skills.

The Buddy Programme provides guidance to all new foundation year students. A Buddy is an older student whose role is to guide and offer friendly support to a small group of new students as they settle in to university. New students are invited to Buddy events, such as a Buddy Treasure Hunt held on campus, which also serves to help new students get to know the campus environment and make new friends in new social networks. Student feedback from the Buddy Programme indicates that this is a valuable programme which assists in the integration and acculturation of new students.

\subsection{Student Development and Wellbeing Support}

The student journey at this university commences with orientation. Orientation days for new students are held at the beginning of each academic year, and comprises a comprehensive induction programme. Social activities are tailored to introduce the students to university life. To supplement and extend the initial orientation, a rolling orientation programme is offered during the first six weeks which includes important elements for student integration and 
acculturation to the university's ethos and environment at key points of time in the academic programme when such information is required. This is to avoid information overload during orientation and to introduce information to new students when and as they need it.

Student academic success, progress and wellbeing are key aspects of a student journey. This university operates two important units which focus on the transitional elements of student success and wellbeing.

Firstly, designed by students for students, the university's Centre for Student Success (CSS) plays a pivotal role in supporting students' academic, personal and professional growth. The CSS provides a comfortable, informal and friendly space where students can drop in to consult with two full-time learning tutors, relax in the lounge area, access self-help learning resources and anatomy models, find out about the many extra-curricular learning activities and workshops which support the official curriculum, and seek learning support and guidance. The Centre also offers a varied range of learning spaces to suit individual learning styles. A specific programme, PASS (Personal and Academic Student Success) has been developed to support poorly performing students.

Secondly, the Student Health and Wellbeing Unit (SHWU) focuses on the psychosocial and emotional aspect of supporting new students. Students can access confidential counselling and pastoral services, disability advice and lifestyle and health guidance. The SHWU also delivers workshops such as stress management, runs regular events and awareness campaigns to promote a balanced student lifestyle of healthy living and academic progress.

The CSS and the SHWU teams deliver over 100 group sessions and workshops in an academic year. Such para academic initiatives are essential in delivering a successful transnational student experience.

\section{Conclusion and Recommendations}

This paper has investigated the journey embarked upon by foundation year medical students which includes adapting to new ways of learning, knowing and developing self-determination as they navigate the new situated spaces of a transnational medical university in the Middle East. Drawing on a body of research carried out in the university, we have discussed the complexities involved for local students on a transnational educational journey. We emphasize the ontological and epistemological shift which occurs as students move from a 'known place' of Arabic secondary school, to a 'new space' of transnational learning. Specific challenges confronted by local students in transnational medical education as they make sense of their new world were highlighted, such as language. We propose a tri-support model (figure 4) which depicts this ontological and epistemological shift, and highlight the underlying support areas which address the transitional needs in this context of foundation year medical students in transnational education.

Recommendations drawn from this paper focus on the need for transnational universities to be cognizant of the often unaddressed issues of language and transition. Ontological and epistemological challenges for local students in each transnational education context should be identified, and specific support mechanisms to bridge gaps for these students developed, such 
as those highlighted above. We call for institutions of transnational education to rethink traditional modes of first year student support. Particular attention should be paid to the cultural frame of reference of students where institutions of transnational education operate; the global-local fields of transnational education open up new spaces and a vista of opportunities which, in our context, informs our practice for the education and socialization of a unique professional persona of local Arabic medical students as they successful transition to become global healthcare practitioners.

\section{References}

Arulampalam, W., Naylor, R. A., \& Smith, J. P. (2003). A hazard model of the probability of medical school dropout in the United Kingdom. Journal Royal Statistical Society, 167, 157-78. https://doi.org/10.1046/j.0964-1998.2003.00717.x

Badenhorst, E., \& Kapp, R. (2013). Negotiation of learning and identity among first-year medical students. Teaching in Higher Education, 18(5), 465-476. http://dx.doi.org/10.1080/13562517.2012.753050

Baxter- Magolda, M. B. (1992). Knowing and Reasoning in College: gender related patterns in students' intellectual development. San Francisco: Jossey-Bass.

Beachboard, M. R., Beachboard, J. C., Li, W., \& Adkison, S. R. (2011). Cohorts and relatedness: Self-determination theory as an explanation of how learning communities affect educational outcomes. Research in Higher Education, 52(8), 853-874. https://doi.org/10.1007/s11162-011-9221-8.

Biggs, J. (1998). Learning from the Confucian heritage: So size doesn't matter? International Journal of Educational Research, 29, 723-738. https://doi.org/10.1016/S0883-0355(98)00060-3

Bourdieu, P. (1991). Language and Symbolic Power. Cambridge, MA: Harvard University Press.

Braun, V., \& Clarke, V. (2006). Using thematic analysis in psychology. Qualitative research in psychology, 3(2), 77-101. http://dx.doi.org/10.1191/1478088706qp063oa

Brooks, C. F., \& Young, S. L. (2011). Are Choice-Making Opportunities Needed in the Classroom? Using Self-Determination Theory to Consider Student Motivation and Learner Empowerment. International Journal of Teaching and Learning in Higher Education, 23(1), 48-59. http://files.eric.ed.gov/fulltext/EJ938578.pdf

Deci, E. L., \& Ryan, R. M. (eds). 2002. Handbook of self-determination research. University of Rochester Press.

Dornan, T., Pearson, E., Carson, P., Helmich, E., \& Bundy, C. (2015). Emotions and identity in the figured world of becoming a doctor. Medical education, 49(2), 174-185.

Dutton, K. et al. (2010). Expectation, Experience and the Conceptualisation of Higher Education amongst Students. Chester: University of Chester. 
http://ganymeade.chester.ac.uk/index.php?page_id=242343\&group=3.

Enns, C. (2010). Locational feminisms and feminist social identity analysis. Professional Psychology, Research \& Practice, 41, 333-339. http://dx.doi.org/10.1037/a0020260

Gale, T. \& Parker, S. (2014). Navigating change: A typology of student transition in higher education. Studies in Higher Education, 39(5), 737-753. http://dx.doi.org/10.1080/03075079.2012.721351

Gay, G. (2010). Culturally responsive teaching: Theory, research, and practice (2nd ed.). New York: Teachers College Press.

Guba, E. G., \& Lincoln, Y. S. (1998). Competing paradigms in qualitative research. In the Landscape of Qualitative Research. In N. K. Denzin \& Y. S. Lincoln, (Eds.). Sage: Thousand Oaks,CA. pp195-222.

Hanson, L., Harms, S., \& Plamondon, K. (2011). Undergraduate international medical electives: some ethical and pedagogical considerations. Journal of Studies in International Education, 15(2), 171-185. https://doi.org/10.1177/1028315310365542

Haw, K. (2011). The 'changing same'of an 'in-between'generation: negotiating identities through space, place and time. Discourse: studies in the cultural politics of education, 32(4), 565-579. http://dx.doi.org/10.1080/01596306.2011.601553

Hayes, A., Holden-Rachiotis, C., Kavanagh, B., \& Otoom, S. (2011). Bridging the gap: on easing the transition from Arab secondary to Western third level learning. Evaluation \& Research in Education, 24(2), 105-120. http://dx.doi.org/10.1080/09500790.2010.55028

Hayes, A., Holden, C., Gaynor, D., Kavanagh, B., \& Otoom, S. (2013). Bridging the gap: a program to enhance medical students' learning experience in the foundation year. Bahrain Medical Bulletin, 35(4), 196-200. Retrieved from http://epubs.rcsi.ie/cgi/viewcontent.cgi?article=1008\&context=biolart.

Hayes, S. C., \& Farnill, D. (1993). Medical training and English language proficiency. Medical education, 27(1), 6-14. http://dx.doi.org/10.1111/j.1365-2923.1993.tb00222.x

Holden, C. (2015) A case study investigation into success and failure in Foundation Year Medical School in a Middle Eastern transnational context (EdD Thesis for Institute of Education, Institute of Education, UCL).

Holden, C., \& Otoom, S. (2015). Bridging the Gap: The Need for Research in the Middle East. Bahrain Medical Bulletin, 37(2), 83-84. Retrieved from http://www.bahrainmedicalbulletin.com/June_2015/Editorial_II.pdf

Houser, M. L., \& Frymier, A. B. (2009). The role of student characteristics and teacher behaviors in students' learner empowerment. Communication Education, 58(1), 35-53. Retrieved from http://jsi.sagepub.com/content/11/3-4/290.

Kane, T. (2014). Whose Lingua Franca? The Politics of Language in Transnational Medical Education. The Journal of General Education, 63(2-3), 94-112. 
http://dx.doi.org/10.1353/jge.2014.0015

Kim, S., \& Slapac, A. (2015). Culturally responsive, transformative pedagogy in the transnational era: Critical perspectives. Educational Studies, 51(1), 17-27. http://dx.doi.org/10.1080/00131946.2014.983639

King, J. T. (2004). Service-Learning as a site for critical pedagogy: A case of collaboration, caring, and defamiliarization across borders. Journal of Experiential Learning, 26(3), 121-137. https://doi.org/10.1177/105382590402600304

Kruzicevic, S. M., Barisic, K. J., Banozic, A., Esteban, C. D., Sapunar, D., \& Puljak, L. (2012). Predictors of attrition and academic success of medical students: a 30-year retrospective study. PloS one, 7(6), e39144. doi39144.doi.1371/journal.pone.0039244.

Leksandar-Hayes, A. M. (2013). Students' and teachers'views of transition from secondary education to western medical university in Bahrain. (PhD Thesis. UK: University of Exeter). https://ore.exeter.ac.uk/repository/handle/10871/13927

Lindley, J., McCall, L., \& Abu-Arab, A. (2013). Visitor or inhabitant? Addressing the needs of undergraduate transnational medical students. Journal of Studies in International Education, 17(1), 79-96. https://doi.org/10.1177/1028315311431894

Maddison, W. (2016). Developing a Transnational Student Success 'Signature'. World Academy of Science, Engineering and Technology: Educational and Pedagogical Sciences, 9(5). Retrieved from http://waset.org/publications/10001127/transnational-highereducation-developing-a-transnational-student-success-signature-for-pre-clinical-medical- stud ents-an-action-research-project.

Maddison, W. (2015). Transnational Higher Education: Developing a Transnational Student Success' Signature'for Pre-Clinical Medical Students-An Action Research Project. World Academy of Science, Engineering and Technology, International Journal of Social, Behavioral, Educational, Economic, Business and Industrial Engineering, 9(5), 1390-1395.

Marginson, S. (2014). Student self-formation in international education. Journal of Studies in International Education, 18(1), 6-22. https://doi.org/10.1177/1028315313513036

Marlowe, J. M., Appleton, C., Chinnery, S. A., \& Van Stratum, S. (2015). The Integration of Personal and Professional Selves: Developing Students' Critical Awareness in Social Work $\begin{array}{llll}\text { Practice. } & \text { Social } & \text { 6ork } & \text { 6ducation, }\end{array}$ http://dx.doi.org/10.1080/02615479.2014.949230

Milyavskaya, M., \& Koestner, R. (2011). Psychological needs, motivation, and well-being: A test of self-determination theory across multiple domains. Personality and Individual Differences, 50(3), 387-391. https://doi.org/10.1016/j.paid.2010.10.029

Patel, F., \& Lynch, H. (2013). Globalization as an Alternative to Internationalization in Higher Education: Embedding Positive Global Learning Perspectives. International Journal of Teaching and Learning in Higher Education, 25(2), 223-230. Retrieved from http://www.isetl.org/ijtlhe/pdf/IJTLHE1484.pdf 
Patton, M. Q. (1990). Qualitative evaluation and research methods. Second Edition. Sage.

Pitkethly, A., \& Prosser, M. (2001). The first-year experience project: A model for university-wide change. Higher Education Research and Development, 20(2), 185-98. http://dx.doi.org/10.1080/758483470

Ryan, R. M., \& Deci, E. L. (2000). Self-determination theory and the facilitation of intrinsic motivation, social development, and well-being. American Psychologist, 55, 68-78. http://dx.doi.org/10.1037/0003-066X.55.1.68

Sinclair, H. K., \& Cleland, J. A. (2007). Undergraduate medical students: who seeks formative feedback? Medical Education, 41, 580-582. http://dx.doi.org/10.1111/j.1365-2923.2007.02768.x

Sohail, M. S., \& Shaikh, N. M. (2004). Quest for excellence in business education: a study of student impressions of service quality. The International Journal of Educational Management, 18(1), 58-65. https://doi.org/10.1108/09513540410512163

Stütz, A., Green, W., McAllister, L., \& Eley, D. (2015). Preparing medical graduates for an interconnected world: Current practices and future possibilities for internationalizing the medical curriculum in different contexts. Journal of Studies in International Education, 19(1), 28-45. https://doi.org/10.1177/1028315314536991

Taha, N., \& Cox, A. (2016). International students' networks: a case study in a UK university. Studies in Higher Education, 41(1), 182-198. https://doi.org/10.1080/03075079.2014.927851.2.

Tinto, V., \& Goodsell-Love, A. (1993). Building Community. Liberal Education, 79(4), 16-22. https://eric.ed.gov/?id=EJ479696

Tinto, V. (1994). Leaving college: Rethinking the causes and cures of student attrition. Chicago: The University of Chicago Press.

Torenbeek, M., Jansen, E. P., \& Hofman, W. A. (2011). How is the approach to teaching at secondary school related to first-year university achievement?. School Effectiveness and School Improvement, 22(4), 351-370. http://dx.doi.org/10.1080/09243453.2011.577788

Trotter, E., \& Roberts, C. A. (2006). Enhancing the early student experience. Higher Education Research \& Development, 25(4), 371-386. https://doi.org/10.1080/07294360600947368

Wenger, E. (1998). Communities of practice: Learning, meaning, and identity. Cambridge: Cambridge University Press.

Wigfield, A., \& Eccles, J. S. (Eds.). (2002). The development of achievement motivation. San Diego, CA/London, UK: Academic Press.

Wu, W., \& Hammond, M. (2011). Challenges of university adjustment in the UK: a study of East Asian Master's degree students. Journal of Further and Higher Education, 35(3), 423-438. http://dx.doi.org/10.1080/0309877X.2011.569016 


\section{Macrothink}

International Journal of Learning and Development

ISSN 2164-4063 2017, Vol. 7, No. 4

Yorke, M., \& Longden, B. (2007). The first-year experience in Higher Education in the UK. York: Higher Education Academy.

\section{Copyright Disclaimer}

Copyright for this article is retained by the author(s), with first publication rights granted to the journal.

This is an open-access article distributed under the terms and conditions of the Creative Commons Attribution license (http://creativecommons.org/licenses/by/4.0/). 